\title{
Mercury releasing from amalgam with disinfectan solution
}

\author{
Viona Diansari*, Ellyza Herda** \\ ${ }^{*}$ Magister Programme Student of Dental Basic Science with speciality on Dental Material Science \\ Faculty of Dentistry Universitas Indonesia \\ **Department of Dental Material Science Faculty of Dentistry Universitas Indonesia
}

\begin{abstract}
Amalgam is widely used for posterior restoration because of its strength compare to the other restorative materials. However, the mercury released in amalgam still becomes a controversy, and its harmfull effects to human. Researches show that the mercury released occurs when mercury ion is dissolved in acid or oxidizing solutions. In dentristry, disinfectan that is used for sterilizing instruments, such as hand instrument and handpiece previously used during the replacement process of amalgam restoration can make mercury dissolving from amalgam residue in the instruments. The number of mercury ion dissolving in disinfectan solution depends on disinfectan's pH, concentration, contact time, redox potencial, and $\mathrm{Sn}$ content in amalgam matrix phase Ag-Hg. The process of mercury released from amalgam to disinfectan solutions is caused by the ability of disinfectan in oxidizing mercury metal (elemental) to become the dissolvable mercury ion. Therefore, dentists and clinicans should be carefully certain procedures of disinfectan waste disposal that contain mercury ion, in order to avoid toxic contamination of mercury ion that can be dangerous to the environment.
\end{abstract}

Key words: Mercury releasing, amalgam, disinfectan

\section{INTRODUCTION}

Amalgam restoration is still used all over the world until today. It is because amalgam has several benefits, namely its affordable price, high strength, long-lasted durability and easy manipulation. On one hand, many dentists still have amalgam as the restoration material, especially dentists in remote areas where no other modern restoration materials exist. On the other hand, mercury released from amalgam restoration is still worrying because it can harm human's health. Nonetheless, Spencer ${ }^{1}$ stated that mercury release from amalgam both in form of vapor and ion is still at a low level ranging 2-5 $\mu$ per day.
Mercury release from amalgam possibly occurs through evaporation that produces mercury vapor and through amalgam degradation, which is the electrochemical corrosion or oxidation phase in amalgam, that creates mercury products. ${ }^{2}$ Mercury vapor release usually occurs during manipulation process when doing trituration or amalgam restoration removal. ${ }^{3}$ Meanwhile, corrosion in amalgam often occurs in low-copper amalgam because it has gamma-2 phase $\left(\mathrm{Sn}_{7}\right.$ ${ }_{8} \mathrm{Hg}$ ) with weak mechanical characteristic and vulnerability for corrosion. ${ }^{3,4}$ Therefore, many efforts are performed to improve safe use of amalgam, e.g. dentists must wear a mask during manipulation and use high-copper amalgam which

Correspondence author: Viona Diansari, Department of Dental Material Science \& Technology Faculty of Dentistry Universitas Indonesia Jl. Salemba Raya No.4 Jakarta Pusat 10430, West Java-Indonesia. 
is more resistant to corrosion.

In fact, in amalgam, mercury is in the form of phase or inorganic mercury. ${ }^{5}$ In these forms, mercury is not toxic but it only causes allergic reaction or immune response to sensitive patients. ${ }^{6}$ Mercury becomes dangerous or toxic in vapor, element or ion forms. Mercury ions are possibly formed by mercury solubility and, according to Marek ${ }^{7}$, in low $\mathrm{pH}$ the mercury solubility is high and fast.

The use of disinfectant which usually has low $\mathrm{pH}$ in sterilizing dental instruments to prevent bacterial and dangerous biological organism contamination is one of the procedures that needs to be taken. It is also definitely applicable to dental tool sterilization which has been used for either amalgam restoration production or amalgam restoration removal; therefore it is presumed that disinfectant solution can also cause mercury solubility from amalgam left-over in those dental instruments.

This paper discusses the mechanism of mercury release from amalgam which is caused by disinfectant solution. By knowing the aforementioned issue, it is hoped that dentists and dental nurses will be more careful of handling disinfectant waste that contains mercury in order to avoid polluting environment with toxic mercury ions.

\section{Amalgam}

Amalgam is a restoration material which has been used for more or less 100 years. Amalgam development has been through several periods starting from first generation of amalgam which was made popular by GV Black, second generation known as low-copper amalgam, dispersed amalgam as the third generation, single composition amalgam as the fourth generation, mixture of quaternary alloys as the fifth generation, and high-amalgam with palladium addition as the sixth amalgam. Nowadays, the sixth generation of amalgam has still been used as tooth restoration material. 5

Tooth amalgam can be identified as mixture of silver $(\mathrm{Ag})$, tin $(\mathrm{Sn})$, cuprum $(\mathrm{Cu})$, and a small amount of zinc $(\mathrm{Zn})$, indium $(\mathrm{In})$, palladium $(\mathrm{Pd})$, and selenium (Se) with the addition of mercury (Hg). Mixture of amalgam powder can be produced by two ways, comprising: lathe cutting and milling an ingot to produce a particle called irregular or lathe cut, and by atomizing mixed liquid so it produces a spherical particle form. ${ }^{4}$

Based on the copper amount, amalgam can be classified into low-copper amalgam ( $\mathrm{Cu}=2-5 \%)$ and high copper amalgam (Cu=20-40\% for admixed containing lathe cut and spherical particles; $\mathrm{Cu}=13-30 \%$ for unicomposition that only contains spherical particles). Meanwhile, based on its particle forms, amalgam is classified into irregular or lathe cut amalgam and spherical amalgam. ${ }^{4}$

Technically, the mixing of mixed amalgam powder with mercury is called trituration. Its result in form of plastic mass can be inserted into tooth cavities using a special device; this process is called condensation which can create a good restoration adaptation on cavity walls and let out excess mercury and reduce porosity. Next, carving to get a filling anatomy suitable with tooth curve, burnishing to add filling adaptation suitable with tooth curve, cleansing mercury left-over and decreasing porous on the surface are done. Finally finishing and polishing are done in order to make amalgam surface smoother and shinier. Smooth and shiny surface is more tarnished and corrosion resistant. ${ }^{4.5}$

During triturating, amalgamation reaction occurs in which mercury will solute mixed particle surface (dissolution) that causes a new phase (precipitation) which has higher solution level than in normal temperature that can occur in mouth. ${ }^{5}$ Amalgamation reaction or the hardening of amalgam is a multiphase. But the reaction that happen in low copper amalgam is:

$$
Y\left(\mathrm{Ag}_{3} \mathrm{Sn}\right)+\mathrm{Hg} \rightarrow \mathrm{Y}\left(\mathrm{Ag}_{3} \mathrm{Sn}\right)+\mathrm{Y}_{1}\left(\mathrm{Ag}_{2} \mathrm{Hg}_{3}\right)+\mathrm{Y}_{2}\left(\mathrm{Sn}_{7-8} \mathrm{Hg}\right)
$$

Dominant phase: $\mathrm{\gamma} 1=54-56 \%$ vol, while phase $\gamma=$ 27-35\% dan $\gamma_{2}=11-13 \%$

For admixed high copper amalgam is divided in two phase, are:

First reaction:

$$
\begin{gathered}
Y\left(\mathrm{Ag}_{3} \mathrm{Sn}\right)+\mathrm{Ag}-\mathrm{Cu}(\text { eutetik })+\mathrm{Hg} \rightarrow \mathrm{Y}\left(\mathrm{Ag}_{3} \mathrm{Sn}\right)+\gamma_{1}\left(\mathrm{Ag}_{2} \mathrm{Hg}_{3}\right) \\
+\gamma_{2}\left(\mathrm{Sn}_{7-8} \mathrm{Hg}\right)+\mathrm{Ag}-\mathrm{Cu} \text { (eutetik) }
\end{gathered}
$$

Final reaction is a slow solid-state reaction:

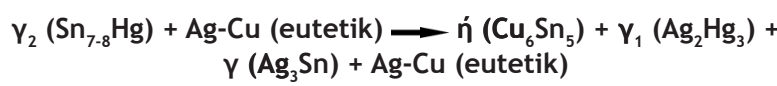


For admixed high copper amalgam unicomposition:

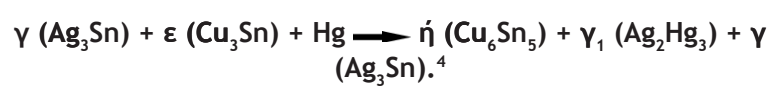

The reaction taking place in low-copper amalgam is: from amalgamation reaction, phase products are resulted forming amalgam structure which contains non-reacted particle left-over and matrix. In low-copper amalgam functioning as matrix: phase $\gamma\left(\mathrm{Ag}_{2} \mathrm{Hg}_{3}\right)$ and $\gamma_{2}\left(\mathrm{Sn}_{7-8} \mathrm{Hg}\right)$, as the booster: particle $\gamma$ leftover $\left(\mathrm{Ag}_{3} \mathrm{Sn}\right)$, whereas in high copper amalgam, matrix: phase $\gamma_{1}\left(\mathrm{Ag}_{2} \mathrm{Hg}_{3}\right)$ and booster: phase $\eta\left(\mathrm{Cu}_{6} \mathrm{Sn}_{5}\right)$ planted in gamma-1 particle and particle $\mathrm{y}$ leftover $\left(\mathrm{Ag}_{3} \mathrm{sn}\right)$. Based on its structure, it will affect its characteristics and application. The existence of phase gamma-2 in low-copper amalgam can reduce its mechanical characteristics and also its corrosion resistant. Whereas in high copper amalgam, there is not any phase gamma-2, so it is more resistant to corrosion and the existence of phase eta in hexagonal structure which is planted to in either phase gamma-1 matrix or intergranular gamma-1 makes high-copper amalgam have better mechanical and chemical characteristics. Generally, the mixture of amalgam with high copper is more resistant to fissure propagation. ${ }^{4.5}$

\section{Mercury release in amalgam}

From toxicology perspective, there are three mercury forms: 1) Organic mercury is the most toxic form and is in food substance; 2) Elemental mercury (liquid or steam), its toxic effect appears after it is oxidized to mercury ions which have big affinity towards radical sulfur in protein and in cells, it will form inorganic mercury salt which can impede enzyme functions and protein denaturation, as a consequence cell function and metabolism are impeded; 3) Inorganic mercury in medicine and amalgam filling material. ${ }^{5}$

In amalgam, mercury is bound and formed inter-metallic compound so there is not any free mercury, but this is affected very much by manipulation factors, especially during trituration and condensation. The existence of free mercury can diffuse to dentin surrounding the filling and then enter the pulp through tubulus dentin. As a consequence, it can cause tooth discolorization.
The migration of these mercury atoms is accelerated when there is galvanic current, heat energy or mechanical energy so the heat that appears during finishing and polishing has to be avoided. $^{5}$

Actually, liquid mercury is hard to be absorbed through skin or mucosa. Most mercury is absorbed in ion form before entering blood stream, whereas mercury steam is absorbed more quickly through lungs, and then enter brain blood vessel in a few minutes and is accumulated in the brain. When mercury concentration is high enough, it will cause brain damage, whereas in low concentration, it will cause anxiety, tremor, and focus loss. ${ }^{8}$ That is why, the danger of mercury steam inhalation must be avoided by dentists, although mercury evaporation from amalgam not yet hardening is slower than in pure mercury. ${ }^{5}$

According to Mahler et al. ${ }^{9}$, mercury release is affected by $\mathrm{Sn}$ content in phase matrix $1 \mathrm{1}(\mathrm{Ag}-\mathrm{Hg})$ : when $\mathrm{Sn}$ content in phase $\gamma 1$ gets higher, mercury steam emission decreases. ${ }^{9}$ In fact, mercury release from tooth amalgam can be presses into minimal amount by adding pellet palladium ( $\mathrm{Pd})$ into amalgam during condensation. This technique is a present modification of standard procedure. ${ }^{10}$

It is also supported by the study that Koike et al. ${ }^{11}$ performed showing that mercury evaporation amount during setting powder, mixture of $\mathrm{Ag}-\mathrm{Sn}-\mathrm{Cu}$ is affected by $\mathrm{Pd}$ content both in low-copper amalgam and high-copper amalgam where it showed that after an analysis using Mercury Vapor Analyzer, in 1.5\% Pd addition the amount of mercury steam release decreases, especially in high-copper amalgam (Tytin), it reaches $20-60 \%$ decrease. ${ }^{11}$ Therefore, is it said that ion or mercury steam release from amalgam is far below toxic dose, so it is not dangerous for human's health compared to being exposed to mercury from other sources. Even so, when exposed cumulatively, mercury release in ion or steam form from amalgam can be a real danger for patients, dentists or their assistants. Moreover, mercury toxicity can cause some undiagnosed diseases. ${ }^{12}$ In this case, dentists should be alert to factors that can increase mercury release in amalgam, for example being exposed to heat, acid and other substances, such as tooth whitening and disinfectant. 
Disinfectant effect on mercury release in amalgam

Disinfectant is a substance or solution used for eliminating bacteria and microorganism therefore it can also be used for sterilization, for instance: cast material sterilization, dental instruments or it can also be mixed with mouthwash as antiseptic mouthwash. ${ }^{13}$ Some examples of the most used disinfectant liquid are chlorine (sodium hypochlorite), iodine (iodophor, iodinepovidone), bromide (sodium bromide), aldehyde (glutaraldehyde), phenol (ortho-phenylphenol), ammonium (n-alkyl dimethyl benzyl ammonium chloride) and peroxide/acid peracetat. ${ }^{14}$ Generally disinfectant is acid and acid level of each solution is different, in order chlorine > bromine > iodine > alcanoat acid $>$ aldehyde $>$ phenol $>$ ammonium .

Disinfectant also contains oxidizing substance (oxidator) which will raise mercury release so it can add mercury amount in the environment. ${ }^{15}$ Rotstein's et al. study ${ }^{16}$ performed in vitro to 56 tooth amalgam samples with the same size and were immersed in $10 \mathrm{ml}$ sodium hypochlorite solution $(\mathrm{NaOCl}) 1 \%$ and $3 \%$ for 20 , 40 and 60 minutes showed that mercury release happens more in $\mathrm{NaOCl} 3 \%$ compared with that in $\mathrm{NaOCl} 1 \%$. The addition of buffer 10\% EDTA into $\mathrm{NaOCl} 1 \%$ and $3 \%$ can reduce mercury release. Mercury release in EDTA, distillated water, and buffer phosphate is less than in $\mathrm{NaOCl}$. The amount of mercury content or mercury ion concentration in $\mathrm{NaOCl}$ solution is measured by using cold-vapor atomic absorption Mercury Analyzer System. ${ }^{16}$

Disinfectant containing chlorine can cause abundant mercury release from amalgam. ${ }^{17}$ It is supported by a study performed by Roberts et al. ${ }^{14}$, using high-copper amalgam in the form of ditriturated spherical using amalgamator according to manufacturer recommendation. After it is made in pellet form, it is kept in a container for a month to produce dry amalgam. Next, the alloy amalgam pellet is grinded into powder using standard cutting tools so powder particle is produced in $710-900 \mu \mathrm{m}$ and 20 gram of amalgam powder is weighed and put in close test plastic. After that, $50 \mathrm{ml}$ disinfectant solution is put into it. For each disinfectant solution, there are 5 test samples made. The duration of each disinfectant is 10 minutes for $5,25 \% \mathrm{NaOCl}$, iodine, dualphenol, triphenol, and ammonium, whereas in bromide solution it only takes 5 minutes, and 15 minutes in peroxide solution/parasetat acid. As the control, immersion is done for 10 minutes. ${ }^{14}$

The result shows that the most mercury ion solubility is in chlorine solution $(\mathrm{NaOCl})$ followed by bromine (sodium bromide), iodine (iodophor), peroxide/ parasetat acid, and dualphenol, whereas mercury ion solubility in triphenol produces the same level as distillation water in the control solubility, but in ammonium disinfectant solution mercury ion solubility occurs in a very small amount $(<0,2 \mathrm{ppb})$ and under the result all that is showed by the control. ${ }^{14}$

\section{DISCUSSION}

From the previous studies, it is found that disinfectant solution has the ability to dissolve mercury ion causing mercury ion to release from amalgam. Mercury release mechanism taking place in disinfectant solution which contains oxidator or oxidized substance has a big oxidized power so it can increase electromotive potential (emf) of alloy. As a consequence, conversion or chemical transformation of the mercury element changes or oxidized into mercury ion. Next, mercury ions undergo solution in disinfectant. It is supported by Marek $^{18}$ that mercury solubility is faster in solution which has high oxidation ability, and also hydrogen peroxide content. High and low mercury ion solubility in disinfectant depends on some factors, including:

\section{Acidity level $(\mathrm{pH})$}

In low $\mathrm{pH}$, mercury solubility will be high both for low-copper amalgam and for high-copper amalgam. The study performed by Marek ${ }^{7}$ stated that $\mathrm{Sn}$ oxide layer is easily dissolved in low $\mathrm{pH}$ solution, both for 2 hour contact time and for 24 contact time. Analysis result using Atomic Absorption Spectrophotometer (AAS) shows that mercury solution is very fast in solution with $\mathrm{pH} 1 .{ }^{7}$ It is caused by high solubility of Sn oxide layer in $\mathrm{pH} 1$, whereas in free phase matrix Ag-Hg (does not contain Sn), mercury ion solubility is made faster by $\mathrm{Ag}$ solubility in low $\mathrm{pH}$ solution. Later, Okabe et al. research ${ }^{19}$ examining mercury solubility in deionized water and $\mathrm{pH} 1$ solution after 6 day and 1 month-immersion shows that mercury ion solubility in $\mathrm{pH} 1$ solution is greater than in deinoized water 
both for high-copper amalgam and for low-copper amalgam. ${ }^{19}$

\section{Solution concentration}

The higher disinfectant solution concentration used, the more mercury ion solubility produced such as in a study performed by Rotstein et al. ${ }^{16}$ which showed that mercury release is produced more in $\mathrm{NaOCl} 3 \%$ compared to $\mathrm{NaOCl} 1 \%$.

\section{Contact time}

By the increase of contact time or disinfectant solution exposure to amalgam, the more mercury release is produced as shown in a study conducted by Okabe et al. ${ }^{19}$ They examined mercury solubility in deionized water and solution with pH1 after the 6 day and 1 month - immersion which showed that either high-copper amalgam or low-copper amalgam experienced higher mercury ion solubility in $\mathrm{pH} 1$ with 1 month-contact time rather than 6 day-contact time. In 6 day immersion, mercury ion solubility of high-copper amalgam is smaller than low-copper amalgam ${ }^{19}$ because phase $\mathrm{\gamma} 1\left(\mathrm{Sn}_{7-8} \mathrm{Hg}\right)$ in low-copper amalgam oxidizes into ions more easily, whereas a-1 month- mercury ion solubility of high-copper amalgam is extremely greater than that of low-copper amalgam. It is because there is phase $\mathrm{\gamma} 1\left(\mathrm{Ag}_{2} \mathrm{Hg}_{3}\right)$ in high-copper amalgam which contains more mercury than phase Y2 $\left(\mathrm{Sn}_{7-8} \mathrm{Hg}\right)$ in low-copper amalgam, but by adding $\mathrm{pH}$ into high-copper amalgam, it can reduce mercury ion release from copper. ${ }^{20}$

\section{Potential of disinfectant solution redox}

Mercury ion release occurs more in disinfectant solution which has potential redox and big corrosion. As indicated in a study conducted by Roberts et al. ${ }^{14}$, that mercury ion solubility is extremely greater in $\mathrm{NaOCl} 5,25 \%$ than in ammonium. It is because of redox and corrosion potential differentiation between the two disinfectant solutions. Redox and corrosion potential of ammonium is smaller, which is $+0,086$ and $-0,285$ volt, whereas $\mathrm{NaOCl}$ solution has redox potential $+0,642$ volt and corrosion potential $+0,082$ Volt. As a consequence ammonium ability to oxidize $\mathrm{Hg}$ element in phase $\mathrm{\gamma} 1\left(\mathrm{Ag}_{2} \mathrm{Hg}_{3}\right)$ into mercury ions slows so within the same immersion time as $\mathrm{NaOCl}$ time immersion, produces smaller mercury ion solubility.

\section{Sn content in phase matrix $\mathrm{Ag}-\mathrm{Hg}$}

Mercury ion solubility is affected by electrode potential of phase matrix $\gamma^{1}(\mathrm{Ag}-\mathrm{Hg})$ in tooth amalgam ${ }^{21}$ but is affected more by $\mathrm{Sn}$ content in phase matrix Ag-Hg. Loads of Sn content provides $\mathrm{Sn}$ oxide layer on phase matrix $\mathrm{Ag}-\mathrm{Hg}$ surface so it can minimize mercury ion solubility. Analysis result using AAS in the study conducted by Marek ${ }^{18}$ showed that phase matrix Ag-Hg has a lot of slower and less mercury ions solubility than in phase matrix Ag-Hg which does not have small amount of Sn or Sn content. ${ }^{22}$ It happens because mercury release flow is controlled by its diffusion through oxide layer. If there is a lot of Sn content, Sn oxide layer formed will be quite thick thus it can be barrier for mercury solubility, but is $\mathrm{Sn}$ oxide layer dissolves, mercury solubility flow will increase.

\section{CONCLUSION AND SUGGESTION}

From the discussion above and some studies conducted, it can be concluded that disinfectant solution contains oxidizing substance and has low $\mathrm{pH}$ consequently it can cause mercury release from amalgam through mercury ion solubility. High or low level of mercury ion solubility in disinfectant solution depends on $\mathrm{pH}$, concentration, contact time, and redox potential of disinfectant solution which is used, and also Sn content in phase matrix $\mathrm{Ag}-\mathrm{Hg}$ in its amalgam. It is suggested that dentists and their assistants have to be more careful when disposing disinfectant waste which is produced by sterilization process of dental instruments, such as hand instruments and handpiece which have been used for producing and removing amalgam restoration because it is possible that mercury ion solubility from amalgam leftover in those instruments into disinfectant. Furthermore, special handling of disinfectant waste containing the mercury ion is needed. Then, the waste can be collected and processed or recycled by authorized department, therefore pollution caused by toxic and dangerous mercury ions can be avoided. 


\section{REFERENCES}

1. Spencer AJ. Dental amalgam and mercury in dentistry. Aust Dent J 2000;45(4):224-34.

2. Berglund $A$. Release of mercury vapor from dental amalgam. Swed Dent J 1992;85 (Suppl):1-52.

3. Anusavice KJ. Phillips' science of dental materials. $11^{\text {th }}$ ed. Philadelphia: W.B. Saunders; 2003.

4. Craig RG, Powers JM. Restorative dental materials. $11^{\text {th }}$ ed. St. Louis: Mosby; 2002.

5. Herda E. Penambahan paladium didalam amalgam kandungan tembaga tinggi. Thesis. Jakarta: Universitas Indonesia; 1991.

6. Kazantzis G. Mercury exposure and early effects: An overview. Med Lav 2002;93(3):13947.

7. Marek M. Dissolution of mercury from dental amalgam at different $\mathrm{pH}$ values. J Dent Res 1997;76(6):1308-15.

8. Punta B. Pemutihan gigi vital dengan karbamid peroksida $10 \%$ terhadap merkuri dari restorasi amalgam. M I Kedokteran Gigi 2005;61:42936.

9. Mahler DB, Adey JD, Fleming MA. Hg emission from dental amalgam as related to the amount of $\mathrm{Sn}$ in the Ag-Hg (gamma 1) phase. J Dent Res 1994;73(10):1663-8.

10. Neme AL, Wagner WC, O'Brien WJ. Effects of palladium addition on emission of mercury vapor from dental amalgam. Dent Mater 1999;15(6):382-9.

11. Koike M, Ferracane JL, Adey JD, Fujii $\mathrm{H}$, Okabe T. Initial mercury evaporation from experimental Ag-Sn-Cu amalgams containing Pd. Biomaterials 2004;25(16):3147-53.

12. Sturdevant CM, Roberson TM, Heymann
HO, Sturdevant JR. The Art and science of operative dentistry. $3^{\text {rd }}$ ed. Baltimore: Mosby; 1995:219-30.

13. Noort RV. Introduction to dental materials. $2^{\text {nd }}$ ed. London: Mosby; 2002.

14. Roberts HW, Marek M, Kuehne JC, Ragain JC. Disinfectants' effect on mercury release from amalgam. J Am Dent Assoc 2005;136(7):9159.

15. Kielbassa AM, Attin T, Kummerer K, Hellwig E. Mercury release from separated amalgam after the use of different disinfectants. Schweiz Monatsschr Zahnmed 1995;105(12):1534-8.

16. Rotstein I, Karawani M, Sahar-Helft S, Mor C, Steinberg D. Effect of sodium hypochlorite and EDTA on mercury released from amalgam. Oral Surg Oral Med Oral Pathol Oral Radiol Endod 2001;92(5):556-60.

17. Batchu H, Chou HN, Rakowski D, Fan PL. The effect of disinfectants and line cleaners on the release of mercury from amalgam. J Am Dent Assoc 2006;137(10):1419-25.

18. Marek M. Dissolution of mercury vapor in simulated oral environments. Dent Mater 1997;13(5):312-5.

19. Okabe T, Elvebak B, Carrasco L, Ferracane JL, Keanini RG, Nakajima H. Mercury release from dental amalgams into continuously replenished liquids. Dent Mater 2003;19:38-45.

20. Lin TH, Chan CC, Chung KH. Metal release from high-copper amalgams containing palladium. Zhonghua Yi Xue Za Zhi 1994;53(3):146-53.

21. Marek M. The effect of the electrode potential on the release of mercury from dental amalgam. J Dent Res 1993;72(9):1315-9.

22. Marek M. The effect of tin in the Ag-Hg phase of dental amalgam on dissolution of mercury. Dent Mater 1997;13(6):353-9. 